\title{
Utilization of Iron Dextran
}

\author{
A. G. DAVIES, M. R. BEAMISH, A. JACOBS
}

British Medical fournal, 1971, 1, 146-147

\section{Summary}

The utilization of iron dextran was investigated in normal subjects, in patients with iron-deficiency anaemia, and in anaemias associated with rheumatoid arthritis, reticulosis, and uraemia. Utilization of iron for haemoglobin formation at 14 days was found to be depressed in patients with rheumatoid arthritis, reticulosis, and uraemia, but when a concomitant iron-deficiency anaemia was present utilization was significantly increased. When iron dextran is used to treat anaemias in such conditions an optimum therapeutic response will be obtained only when bone marrow iron stores are absent.

\section{Introduction}

When iron dextran (Imferon) is given by intravenous injection it is cleaned by the reticuloendothelial system, where it is metabolized. The iron released is taken up by plasma transferrin and transported to the bone marrow for incorporation into haemoglobin (Golberg, 1958). It has been suggested that in inflammatory conditions, malignant states (Haurani et al., 1963, 1965), and possibly in uraemia (Bothwell and Finch, 1962) reticuloendothelial function is altered so that iron sequestered in the reticuloendothelial cell is not adequately released to take part in haemoglobin synthesis. The use of iron dextran has, however, sometimes been advocated in such patients. Hart (1970) suggested that the reticuloendothelial block of iron release in rheumatoid arthritis might be overcome by the infusion of large doses, and Carter et al. (1969) stated that in uraemic patients iron transport was increased following iron dextran administration. groups were studied: eight healthy male students, five patients suffering from rheumatoid arthritis, five patients with iron-deficiency anaemia, five patients with chronic renal failure, and three patients with untreated malignant reticulosis (two Hodgkin's disease, one lymphosarcoma). The haematological data for these groups are shown in Table I. In the patients with rheumatoid arthritis the Rose-Waaler titre ranged from $1 / 8$ to $1 / 2048$ and the E.S.R. (Westergren) ranged from 52 to $112 \mathrm{~mm}$ in one hour. In the uraemic patients blood urea levels ranged from 68 to $268 \mathrm{mg} / 100 \mathrm{ml}$ and creatinine clearance from 4 to $23 \mathrm{ml} /$ minute.

Standard haematological techniques were used (Dacie and Lewis, 1968). Serum iron and total iron-binding capacities were measured by the method of Young and Hicks (1965). Iron stores were assessed by the examination of bone marrow fragments stained with Perls's reagent. This was not carried out in normal subjects. Complete absence of stainable bone marrow iron was found in all patients with iron-deficiency anaemia, in two patients with rheumatoid arthritis, in one uraemic patient, and in one patient with a reticulosis.

${ }^{59} \mathrm{Fe}$ dextran was prepared (by Mr. G. F. Moss, Fisons Pharmaceuticals Ltd.) with a specific activity of $10 \mu \mathrm{Ci} / \mathrm{ml}$. Each dose of ${ }^{59} \mathrm{Fe}$ dextran containing approximately $1 \mu \mathrm{Ci}$ of ${ }^{59} \mathrm{Fe}$ was diluted in $5 \mathrm{ml}$ of saline and given by slow intravenous injection. The amount of iron given varied from 5 to $30 \mathrm{mg}$. Samples of blood were obtained over the subsequent 14 days for measurements of plasma and red cell radioactivity.

Blood volume estimations were made from body weight and height, the tables of Nadler et al. (1962) being used. Plasma clearance rates were obtained by calculating the regression of $\log$ plasma ${ }^{59} \mathrm{Fe}$ activity against time for the initial clearance phase. The percentage utilization of iron for

TABLE I-Mean ( \pm S.D.) Haematological Indices in Normal and Certain Pathological Conditions

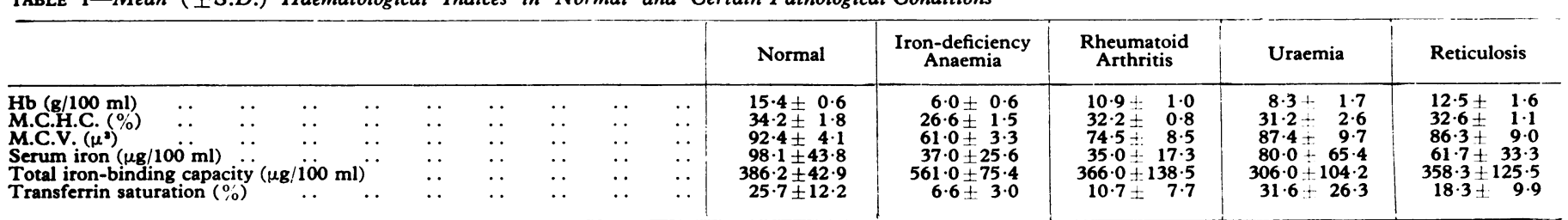

In the present paper we report measurements of iron-dextran clearance from plasma and utilization for haemoglobin formation in normal and anaemic subjects. Some of the anaemic subjects were suffering from uraemia, rheumatoid arthritis, and reticuloendothelial malignancy. These pathological states are associated with reduced utilization of iron given as iron dextran unless iron deficiency is present.

\section{Subjects and Methods}

All subjects were fully informed of the nature of the investigation before their consent was obtained. The following

\section{Cardiff Royal Infirmary, Cardiff CF2 1SZ}

A. G. DAVIES, M.B., M.R.C.P., Medical Registrar

Welsh National School of Medicine, Cardifi CF2 1YE

M. R. BEAMISH, M.B., CH.B., Lecturer in Haematology A. JACOBS, M.D., M.R.C.PATH., Professor of Haematology haemoglobin production was calculated from the red cell activity 14 days after the injection and the activity of the injected dose. This figure does not represent maximum utilization, as some further increase occurs after 14 days. Continuation of tests beyond this time, however, was inconvenient in many cases.

\section{Results}

The half clearance time of plasma radioactivity after injection is shown for each group in Table II. The mean half-time in normal subjects is 14.5 hours. This is significantly reduced in iron-deficient patients $(P<0.02)$ and significantly lengthened in uraemic patients $(\mathrm{P}<0.02)$.

In normal subjects the utilization of injected iron at 14 days was 35 to $62 \%$ (mean $49.5 \%$ ). Patients with iron-deficiency anaemia utilized 64 to $83 \%$ (mean $72.5 \%$ ), which is significantly greater than normal $(P<0.005)$. The mean iron utilization in the other pathological groups did not seem to differ significantly from normal. Inspection of the results, however, 
TABLE II-Initial Rate of ${ }^{59} \mathrm{Fe}$ Dextran Clearance from Plasma

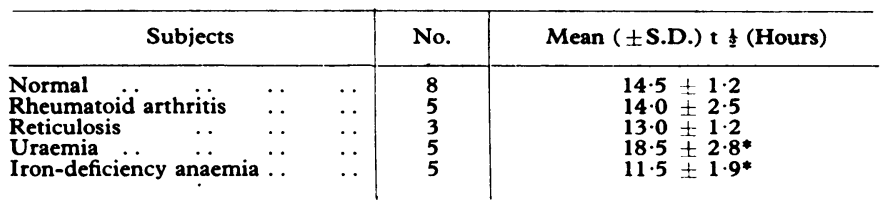

*Significance of difference from normal $P<0.02$.

TABLE III- ${ }^{59} \mathrm{Fe}$ Dextran Utilization at 14 Days in Normal Subjects and Anaemic Patients with and without Bone Marrow Iron Stores

\begin{tabular}{|c|c|c|c|c|}
\hline & Subjects & & No. & Mean $( \pm$ S.D. $) \%$ Utilization \\
\hline $\begin{array}{l}\text { (a) } \\
\text { (b) } \\
\text { (c) }\end{array}$ & $\begin{array}{l}\text { Normal . . . } \\
\text { Anaemic_iron present } \\
\text { Anaemic_iron absent }\end{array}$ & $\begin{array}{l}\ldots \\
\cdots\end{array}$ & $\begin{array}{l}8 \\
9 \\
9\end{array}$ & $\begin{array}{l}49.5 \pm 9 \cdot 3 \\
32.9 \pm 18.5 * \\
75.4 \pm 11.6 t\end{array}$ \\
\hline
\end{tabular}

* Significance of difference from (a) $\mathbf{P}<0.05$. †Significance of difference from $(b)$ $P<0.001$.

showed that the two patients with rheumatoid arthritis who had no stainable iron in the bone marrow had an iron utilization of 68 and $93 \%$ respectively, and the uraemic patient in whom stainable iron was absent had a utilization of $64.5 \%$, all these results being in the iron-deficient range. When the results from all patients are grouped together and divided into those in whom stainable iron was present in the bone marrow and those in whom stainable iron was absent (Table III) it is clear that those who are iron-deficient have a significantly increased iron utilization whereas those in whom stainable iron is present have a significant decrease in utilization.

\section{Discussion}

The rate of disappearance of plasma radioactivity following an intravenous injection of iron dextran is not a simple function. In those of our cases where adequate data were obtained there were at least two exponential components (see Chart)

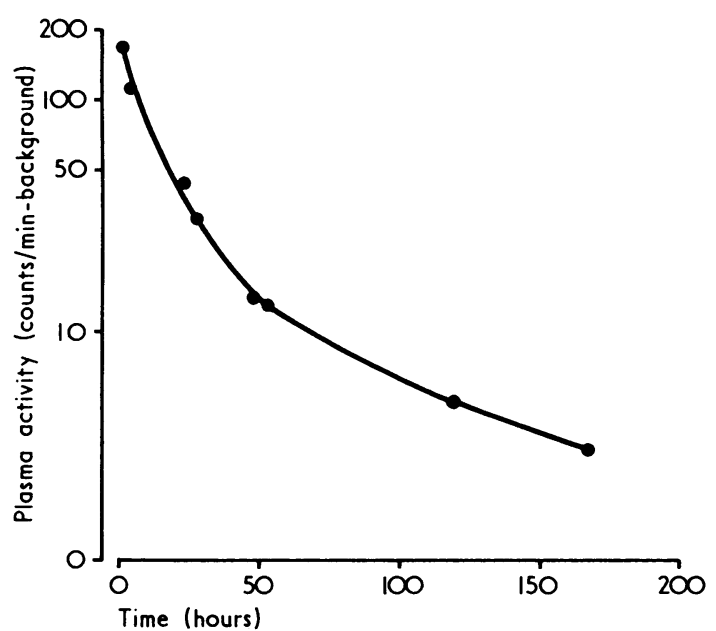

${ }^{59} \mathrm{Fe}$ dextran plasma clearance in a patient with rheumatoid arthritis.

and this has been noted by Wilson and Mills (1970). It is possible that the second of these components is due to the release of iron from reticuloendothelial cells after the breakdown of iron dextran with a subsequent feedback into the plasma pool. The faster clearance of radicactivity in iron-deficient subjects supports this observation, as in such cases transferrin-bound iron would be cleared rapidly to the bone marrow and have little effect on total plasma radioactivity. The decreased rate of clearance in uraemic patients may be partly due to impaired reticuloendothelial uptake and partly to a slower clearance of transferrin-bound iron.

The utilization of iron given as iron dextran is complicated by its initial passage through reticuloendothelial cells. Normal utilization depends both on normal reticuloendothelial uptake and on release of iron, as well as normal uptake of transferrinbound iron by developing red-cell precursors. When iron is released from haemoglobin molecules during the normal catabolic process in reticuloendothelial cells it is rapidly released into the plasma for transport to the bone marrow. In some inflammatory and malignant diseases, however, iron is sequestered within the reticuloendothelial cell and its reutilization for haemoglobin synthesis is therefore impaired. It might be expected that in these conditions iran released from iron dextran would behave in a similar fashion and be poorly utilized by red-cell precursors. In the present study those cases of uraemia, rheumatoid arthritis, and malignant diseases in which stainable iron was present in the bone marrow showed an impaired utilization of iron from iron dextran compared with normal subjects. One of our patients with rheumatoid arthritis showed pronounced microcytic hypochromic anaemia with stainable iron in the bone marrow. Utilization in this case at 14 days was only $37 \%$, suggesting that she may have had defective release of iron from reticuloendothelial cells. One case of reticulosis, one of uraemia, and two cases of rheumatoid arthritis, however, were iron-deficient, as shown by the absence of stainable iron in the bone marrow, and their utilization fell within the range found in uncomplicated iron deficiency.

It appears that if patients are iron-deficient they will have high urilization of iron given as iron dextran irrespective of the underlying disorder. A significant proportion of iron dextran given intravenously is normally sequestered in the reticuloendothelial system (Henderson and Hillman, 1969), and this amount is likely to be increased in patients with abnormal reticuloendothelial function. Our experience suggests that patients will respond optimally only if they are irondeficient, and this is best judged by examination of the marrow for stainable iron. In anaemic patients with evidence of storage iron the administration of parenteral iron will serve only to increase the quantity remaining unutilized in reticuloendothelial cells and will not affect the basic abnormality causing the anaemia.

We thank Dr. J. Henry Jones and Dr. K. N. Lloyd, consultant physicians, United Cardiff Hospitals, for allowing us to study patients under their care; Dr. I. Cavill for help with statistical analysis of the results; and Dr. J. Henry Jones for criticism of the manuscript.

\section{References}

Bothwell, T. H., and Finch, C. A. (1962). Iron Metabolism, p. 162. London, Churchill.

Carter, R. A., Hawkins, J. B., and Robinson, B. H. B. (1969). British Medical Fournal, 3, 206.

Dacie, J. V., and Lewis, S. M. (1968). Practical Haematology, 4th edn. London, Churchill.

Golberg, L. (1958). In Iron in Clinical Medicine, ed. R. O. Wallerstein and S. R. Mettier, p. 74. Berkeley and Los Angeles, University of California Press.

Hart, F. Dudley (1970). British Medical fournal, 2, 747.

Haurani, F. I., Burke, W., and Martinez, E. J. (1965). Fournal of Laboratory and Clinical Medicine, 65, 560.

Haurani, F. I., Young, K., and Tocantins, L. M. (1963). Blood, 22, 73.

Henderson, P. A., and Hillman, R. S. (1969). Blood, 34, 357.

Nadler, S. B., Hidalgo, J. U., and Bloch, T. (1962). Surgery, 51, 224.

Wilson, R. and Mills, I H. (1970) Fournal of Clinical Pathology, 23, 286.

Young, D. S., and Hicks, J. M. (1965). Fournal of Clinical Pathology, 18, 98. 